\title{
Near fatal posterior reversible encephalopathy syndrome complicating chronic liver failure and treated by induced hypothermia and dialysis: a case report Rashmi Chawla ${ }^{1}$, Daniel Smith ${ }^{2}$ and Paul E Marik ${ }^{1 *}$
}

Addresses: ${ }^{1}$ Division of Pulmonary and Critical Care Medicine, Thomas Jefferson University, Philadelphia, PA, USA and ${ }^{2}$ Medical Intensive Care Unit, Thomas Jefferson University Hospital, Philadelphia, PA, USA

Email: PEM* - paul.marik@jefferson.edu

* Corresponding author

\author{
Published: 26 March 2009 \\ Received: 19 September 2008 \\ Journal of Medical Case Reports 2009, 3:6623 doi: 10.1186/1752-1947-3-6623 \\ Accepted: 22 January 2009 \\ This article is available from: http://jmedicalcasereports.com/jmedicalcasereports/article/view/3/3/6623 \\ (C) 2009 Chawla et al; licensee Cases Network Ltd. \\ This is an Open Access article distributed under the terms of the Creative Commons Attribution License (http://creativecommons.org/licenses/by/3.0), \\ which permits unrestricted use, distribution, and reproduction in any medium, provided the original work is properly cited.
}

\begin{abstract}
Introduction: Posterior reversible encephalopathy syndrome is a clinico-neuroradiological entity characterized by headache, vomiting, altered mental status, blurred vision and seizures with neuroimaging studies demonstrating white-gray matter edema involving predominantly the posterior region of the brain.

Case presentation: We report a 47-year-old Caucasian man with liver cirrhosis who developed posterior reversible encephalopathy syndrome following an upper gastrointestinal hemorrhage and who was managed with induced hypothermia for control of intracranial hypertension and continuous veno-venous hemodiafiltration for severe hyperammonemia.

Conclusion: We believe this is the first documented case report of posterior reversible encephalopathy syndrome associated with cirrhosis as well as the first report of the use of induced hypothermia and continuous veno-venous hemodiafiltration in this setting.
\end{abstract}

\section{Introduction}

Posterior reversible encephalopathy syndrome (PRES), first described by Hinchey and colleagues in 1996, is a cliniconeuroradiological entity characterized by headache, vomiting, altered mental status, blurred vision and seizures with neuroimaging studies demonstrating white-gray matter edema involving predominantly the posterior region of the brain [1]. PRES is most commonly associated with hypertensive encephalopathy, eclampsia, porphyria and immunosuppressive or cytotoxic drugs $[1,2]$. Magnetic resonance imaging (MRI) is the diagnostic test of choice, demonstrating hyperintense echoes on T2-weighted images of the parietal-occipital lobes; however, the cerebellar hemispheres, basal ganglia, frontal lobes and brainstem are often involved. While usually completely reversible, a delay in the diagnosis and treatment may result in death or irreversible neurological sequela $[1,3]$. We present a patient with liver cirrhosis who developed PRES following an upper gastrointestinal hemorrhage and who was managed with induced hypothermia for control of intracranial 
hypertension and continuous veno-venous hemodiafiltration (CVVHDF) for severe hyperammonemia.

\section{Case presentation}

A 47-year-old Caucasian man with a past medical history significant for noninsulin-dependent diabetes mellitus, hepatitis $\mathrm{C}$, past alcohol abuse and cirrhosis was admitted to our medical intensive care unit with an upper gastrointestinal bleed. On presentation, his blood pressure was $104 / 70 \mathrm{mmHg}$, heart rate 137 beats per minute, temperature $37.2^{\circ} \mathrm{C}$ and respiratory rate 24 breaths per minute. On examination, he was pale and icteric, and had a mildly distended abdomen with no discernable organomegaly. Cardio-respiratory examination was normal. He was confused and agitated with no focal neurological signs. His white blood count was elevated at $23.7 \times 10^{9 /} / \mathrm{L}$ with $24 \%$ bands, with a hemoglobin of $78 \mathrm{~g} / \mathrm{L}$ and platelets of $83 \times 10^{9} / \mathrm{L}$. Albumin was $19 \mathrm{~g} / \mathrm{dl}$ (normal 32 to $49 \mathrm{~g} / \mathrm{L}$ ), total bilirubin $83.3 \mu \mathrm{mol} / \mathrm{L}$ (normal 3.4 to $20.4 \mu \mathrm{mol} / \mathrm{L}$ ), aspartate aminotransferase (AST) $32 \mathrm{IU} / \mathrm{L}$ (normal 7 to $42 \mathrm{IU} / \mathrm{L}$ ), alanine aminotransferase (ALT) $35 \mathrm{IU} / \mathrm{L}$ (normal 1 to $45 \mathrm{IU} / \mathrm{L}$ ), alkaline phosphatase (ALP) $32 \mathrm{IU} / \mathrm{L}$ (normal 25 to $120 \mathrm{IU} / \mathrm{L}$ ), international normalized ratio (INR) of 1.84 , arterial ammonia $151 \mu \mathrm{mol} / \mathrm{L}$ (normal 11 to $35 \mu \mathrm{mol} / \mathrm{L}$ ) and lactate of $6.1 \mathrm{mmol} / \mathrm{L}$ (normal 0.6 to $1.7 \mathrm{mmol} / \mathrm{L}$ ). His blood urea nitrogen (BUN) and creatinine were $9 \mathrm{mmol} / \mathrm{L}$ and $124 \mu \mathrm{mol} / \mathrm{L}$, respectively.

The patient was electively intubated for airway protection and to facilitate endoscopy. He was resuscitated with crystalloids, 5\% albumin, packed cells and fresh frozen plasma and treated with vancomycin and piperacillin/ tazobactam for presumed sepsis. Ultrasound and Doppler of his upper quadrants was consistent with cirrhosis with normal blood flow and splenomegaly. An upper endoscopy revealed grade 4 esophageal varices with no active bleed. Over the next few days, the patient became progressively unresponsive (off sedation) with his ammonia level rising above $200 \mu \mathrm{mol} / \mathrm{L}$ despite aggressive treatment with lactulose and rifaximin. Neurologic assessment revealed posturing to painful stimuli with a poorly reactive pupillary reflex. Computed tomography of the head revealed diffuse white matter edema prominent in the posterior temporal, parietal and occipital lobes. Brain MRI confirmed diffuse white matter edema with temporal and occipital lobe predominance consistent with the diagnostic pattern for PRES (Figure 1a and 1b). His course was complicated by the development of tonic-clonic seizures which were controlled with intravenous levetiracetam. His pupils became fixed and non-responsive. Transcranial Dopplers (TCD) of the middle and posterior cerebral arteries demonstrated a marked reduction in cerebral blood velocity consistent with severely increased intracerebral pressure (ICP). As an extraordinary salvage method to control the patient's severe ICP, we lowered his core body temperature to $32^{\circ} \mathrm{C}$ with the addition of propofol and mannitol, titrated to keep serum osmolarity $<310 \mathrm{mmol} / \mathrm{L}$. Induced hypothermia was maintained for 48 hours during which time he regained normal pupillary reflexes with marked improvement in TCD velocities. During the passive rewarming phase, the patient developed massive hematemesis. He required massive transfusion and Minnesota tube placement as attempted banding via endoscopy was unsuccessful. The patient underwent an emergency transjugular intrahepatic portocaval shunt (TIPS) placement followed by repeat induced hypothermia $\left(32\right.$ to $\left.34^{\circ} \mathrm{C}\right)$. Due to the anticipated increase in the serum ammonia level following the massive gastrointestinal hemorrhage, we initiated high-flow continuous venovenous hemodiafiltration (CVVHD) to facilitate ammonia removal. The CVVHD was associated with a fall in the ammonia level (Figure 2). At this time, the patient was again passively rewarmed and the propofol discontinued. His neurological status improved slowly over the following week becoming more alert and responsive and allowing extubation. A repeat MRI of the brain showed interval improvement in extensive white matter signal abnormality most consistent with resolving PRES. He was discharged home with no neurological sequela apart from amnesia for the entire hospital stay. The patient has returned to work part-time and is currently listed for liver transplantation.

\section{Discussion}

We believe that this is the first documented case of PRES associated with cirrhosis as well as the first report of induced hypothermia for the management PRES and the use of CVVHD for control of hyperammonemia in a cirrhotic patient. The pathogenesis of PRES remains incompletely understood but is probably related to the failure of cerebral autoregulation and endothelial damage [4]. The favored pathogenetic theory suggests autoregulatory disturbance with hyperperfusion, resulting in bloodbrain barrier breakdown with reversible vasogenic edema without cerebral infarction $[2,4]$. However, others have suggested that the triggering event leads to cerebral vasoconstriction, reduced brain perfusion, ischemia and subsequent vasogenic edema [4-6]. It is not known why the posterior circulation is preferentially affected. A possible explanation is the lower sympathetic innervation of the posterior cerebral arterial circulation than in the internal carotid territory, with a consequent reduced autoregulation of already impaired cerebral areas [2].

The cause of PRES in our patient and the association with hyperammonemia is unclear. In patients with acute liver failure and severe hyperammonemia, there is gradual cerebral vasodilation due to loss of cerebral auto-regulation resulting in increased cerebral blood flow and vasogenic edema [7-10]. Using magnetic resonance 

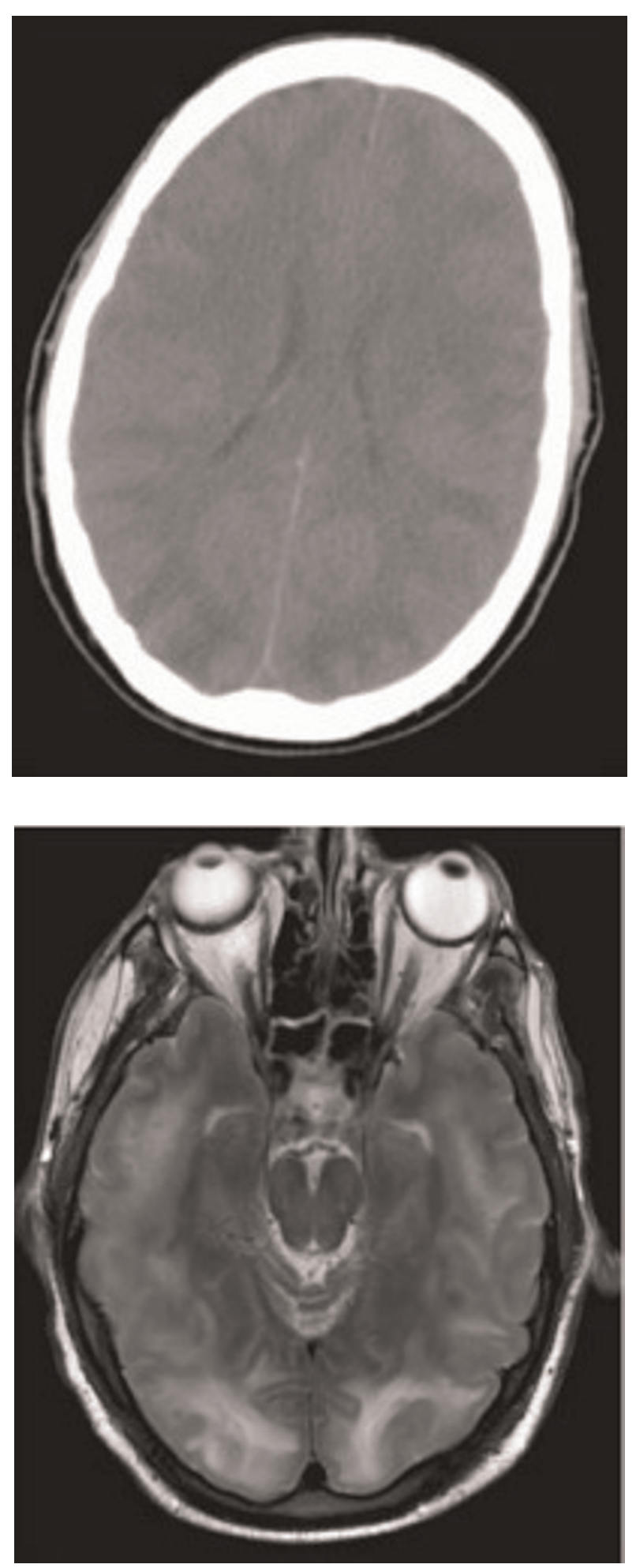

Figure I.

(a) Non-contrast computed tomography showing diffuse cerebral edema. (b) Magnetic resonance image showing multiple cortico-subcortical areas of hyperintense signal involving the occipital and parietal lobes bilaterally and pons.

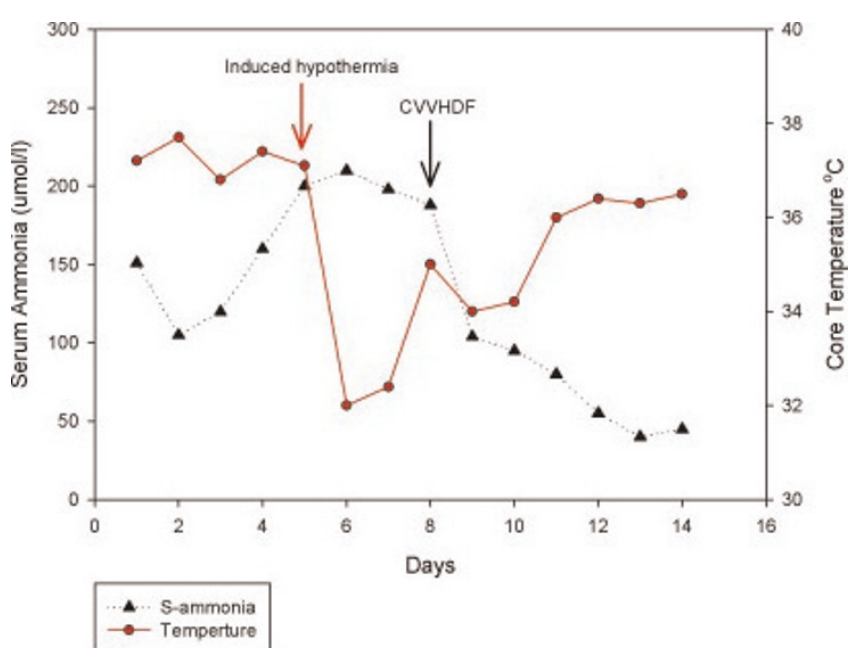

Figure 2.

Time course of arterial ammonia concentration and core body temperature.

diffusion tensor imaging, Kale and colleagues demonstrated an increase in interstitial brain water in patients with cirrhosis and hepatic encephalopathy [11]. In this study, brain water content increased with increasing grade of encephalopathy and decreased with treatment of hyperammonemia. Furthermore, emerging evidence indicates that patients with cirrhosis may have astrocyte swelling and low-grade cytotoxic cerebral edema which is associated with the degree of hyperammonemia $[12,13]$. Our patient presented with hemorrhage and shock complicated by systemic sepsis and required multiple blood transfusions. Bartynski and colleagues have demonstrated that all these factors may be implicated in the etiology of PRES [14].

Our patient's clinical examination, together with the transcranial Doppler and neuroimaging studies suggested that he had severely increased intracranial pressure (ICP) that required aggressive treatment. Due to the patient's coagulopathy, direct ICP monitoring was considered contraindicated. Moderate induced hypothermia has been shown to reduce cerebral edema following cardiac arrest and in patients with acute liver failure $[15,16]$. The mechanisms by which hypothermia reduces neuronal injury and cerebral edema are unknown, however, retardation of destructive enzymatic reactions, suppression of free-radical reactions, protection of the fluidity of lipoprotein membranes, reduction in the oxygen demand in low flow regions, reduction in intracellular acidosis, and inhibition of the biosynthesis, release, and uptake of excitatory neurotransmitters have been postulated [17]. Furthermore, in patients with liver disease, hypothermia reduces cerebral ammonia levels by decreasing brain 
ammonia uptake, decreasing ammonia production and improving ammonia clearance [15]. We believe that the use of induced hypothermia was life saving in our patient. As the cause of PRES was unclear in our patient and because hyperammonemia may cause both vasogenic and cytotoxic edema, we elected to pre-emptively dialyze our patient to reduce the ammonia level. Peritoneal dialysis, hemodialysis, continuous veno-venous hemofiltration (CVVH) and CVVHD have been reported to be helpful in the treatment of hyperammonemia associated with urea cycle disorders in neonates, children and adults. It is unclear whether the use of CVVHDF in our patient contributed to the favorable outcome.

\section{Consent}

Written informed consent was obtained from the patient for publication of this case report and any accompanying images. A copy of the written consent is available for review by the Editor-in-Chief of this journal.

\section{Competing interests}

The authors declare that they have no competing interests.

\section{Authors' contributions}

All authors were directly involved in the care of this patient, were responsible for researching the literature and writing the case report and take responsibility for the final version.

\section{References}

I. Hinchey J, Chaves C, Appignani B, Breen J, Pao L, Wang A, Pessin MS, Lamy C, Mas JL, Caplan LR: A reversible posterior leukoencephalopathy syndrome. N Engl J Med 1996, 334(8):494-500.

2. Servillo G, Bifulco F, De Robertis E, Piazza O, Striano P, Tortora F, Striano S, Tufano R: Posterior reversible encephalopathy syndrome in intensive care medicine. Intensive Care Med 2007, 33:230-236.

3. Narbone MC, Musolino R, Granata F, Mazzu I, Abbate M, Ferlazzo E: PRES: posterior or potentially reversible encephalopathy syndrome? Neurol Sci 2006, 27(3):187-189.

4. Bartynski WS: Posterior reversible encephalopathy syndrome, part 2: controversies surrounding pathophysiology of vasogenic edema. AJNR 2008, 29(6): 1043-1049.

5. Weidauer S, Gaa J, Sitzer M, Hefner R, Lanfermann H, Zanella FE: Posterior encephalopathy with vasospasm: MRI and angiography. Neuroradiology 2003, 45(I2):869-876.

6. Trommer BL, Homer D, Mikhael MA: Cerebral vasospasm and eclampsia. Stroke 1988, 19(3):326-329.

7. Larsen FS, Adel HB, Pott F, Ejlersen E, Secher NH, Paulson OB, Knudsen GM: Dissociated cerebral vasoparalysis in acute liver failure. A hypothesis of gradual cerebral hyperaemia. J Hepatol 1996, 25(2): I 45-I5I.

8. Blei AT, Larsen FS: Pathophysiology of cerebral edema in fulminant hepatic failure. J Hepatol 1999, 3 I (4):77I-776.

9. Jalan R, Olde Damink SW, Deutz NE, Davies NA, Garden OJ, Madhavan KK, Hayes PC, Lee A: Moderate hypothermia prevents cerebral hyperemia and increase in intracranial pressure in patients undergoing liver transplantation for acute liver failure. Transplantation 2003, 75( I 2):2034-2039.

10. Aggarwal S, Obrist W, Yonas H, Kramer D, Kang Y, Scott V, Planinsic R: Cerebral hemodynamic and metabolic profiles in fulminant hepatic failure: relationship to outcome. Liver Transplant 2005, I I (II): I353-1360.

II. Kale RA, Gupta RK, Saraswat VA, Hasan KM, Trivedi R, Mishra AM, Ranjan P, Pandey CM, Narayana PA: Demonstration of interstitial cerebral edema with diffusion tensor MR imaging in type C hepatic encephalopathy. Hepatology 2006, 43(4):698-706.

12. Haussinger D, Kircheis G, Fischer R, Schliess F, Vom DS: Hepatic encephalopathy in chronic liver disease: a clinical manifestation of astrocyte swelling and low-grade cerebral edema? J Hepatol 2000, 32(6): 1035-1038.

13. Norenberg MD, Jayakumar AR, Rama Rao KV, Panickar KS: New concepts in the mechanism of ammonia-induced astrocyte swelling. Metab Brain Dis 2007, 22(3-4):219-234.

14. Bartynski WS, Boardman JF, Zeigler ZR, Shadduck RK, Lister J: Posterior reversible encephalopathy syndrome in infection, sepsis, and shock. AJNR 2006, 27(10):2179-2190.

15. Chatauret N, Rose C, Butterworth RF: Mild hypothermia in the prevention of brain edema in acute liver failure: mechanisms and clinical prospects. Metab Brain Dis 2002, I7(4):445-45I.

16. The Hypothermia after Cardiac Arrest Study Group: Mild therapeutic hypothermia to improve the neurologic outcome after cardiac arrest. N Engl J Med 2002, 346(8):549-556.

17. Bernard SA, Buist M: Induced hypothermia in critical care medicine: a review. Crit Care Med 2003, 3 I(7):204I-205I.

\section{Do you have a case to share?}

Submit your case report today

- Rapid peer review

- Fast publication

- PubMed indexing

- Inclusion in Cases Database

\section{Any patient, any case, can teach us something}

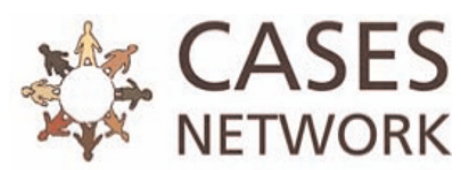

www.casesnetwork.com 